\title{
A new species of tiger beetle from southeastern Arizona and Mexico (Coleoptera, Carabidae, Cicindelini)
}

\author{
Daniel P. Duran', Stephen J. Roman ${ }^{2}$ \\ I Department of Biodiversity, Earth and Environmental Sciences, Drexel University, 3245 Chestnut St., \\ Philadelphia, PA 19104, USA 25335 Oxbow Place, Champlin, MN 55316, USA \\ Corresponding author: Daniel P. Duran (dpd56@drexel.edu)
}

Academic editor: Terry Erwin ${ }^{*}$ | Received 12 August 2014 | Accepted 4 December 2014 | Published 16 December 2014

http://zoobank.org/50F680BE-37C4-43FD-A099-8D9D25062783

Citation: Duran DP, Roman SJ (2014) A new species of tiger beetle from southeastern Arizona and Mexico (Coleoptera, Carabidae, Cicindelini). ZooKeys 464: 35-47. doi: 10.3897/zookeys.464.8424

\begin{abstract}
A new tiger beetle species, Cicindelidia melissa Duran \& Roman, sp. n., of the tribe Cicindelini, is described from high elevation montane forests of southeastern Arizona and Mexico. It appears to be most closely related to C. nebuligera (Bates) but is distinguished on the basis of multiple morphological characters and geographic range. The new species is also superficially similar to the widespread C. sedecimpunctata (Klug), but distinguished on the basis of multiple morphological characters and habitat. Habitus, male and female reproductive structures, and known distribution map are presented.
\end{abstract}

\section{Keywords}

Coleoptera, Cicindelini, Cicindelidia, new species, Arizona, Chiracahua Mountains, Mexico

Subject Editor's Note: This single new species description was accepted due to a need in the forthcoming book by Pearson et al. "A field guide to the Tiger Beetles of the United States and Canada" (Second Edition). Oxford University Press. 


\section{Introduction}

The New World tiger beetle genus Cicindelidia Rivalier (1954) includes approximately 60 described species (Wiesner 1992) and is distributed from Canada south to Chile, reaching its highest diversity in Mexico and the southern United States. Members of the genus are diurnally active insect predators and are typically found in open or sparsely vegetated muddy, rocky, or sandy habitats. The majority of species inhabit areas that range from sea level to mid elevations, with only a few species known to occur at elevations above $2000 \mathrm{~m}$. Herein we describe C. melissa sp. n., an inhabitant of high elevation Ponderosa pine forests and discuss its hypothesized systematic placement within the genus.

\section{Methods}

Specimens of a previously undescribed Cicindelidia had been collected over the past several decades by David Brzoska (Naples, FL), Ron Huber (Bloomington, MN), Walter Johnson (Minneapolis, MN) and John Stamatov (Armonk, NY) from a site in the Chiracahua Mountains of southeastern Arizona and from 29 localities in the Mexican states of Sonora, Chihuahua and Durango. Additional Chiracahua specimens were collected in 2009 by Eric Sangregorio and donated to the first author. In total the authors examined 153 specimens of the new species. Type material is deposited in the following institutional and private collections (acronyms used in the text are in parentheses): National Museum of Natural History, Smithsonian Institution, Washington, DC, USA (NMNH), Arizona State University Frank Hasbrouck Entomology Collection, Tempe, AZ (ASUHIC), Collection of David W. Brzoska, Naples, FL (DWBC), Ronald L. Huber Collection, Bloomington, MN (RLHC), Collection of Walter N. Johnson, MN (WNJC), Collection of Daniel P. Duran, Philadelphia, PA (DPDC), Collection of John Stam atov, Armonk, NY (JSC). Specimens were compared to material of all putative close relatives, including C. sedecimpunctata and it's subordinate taxa mellyi and sallei, C. flohri, and C. nebuligera.

Images of the dorsal, lateral, and frontal habitus and elytral apex were captured using a Canon EOS 7D attached to a Visionary Digital Imaging System (Visionary Digital, Palmyra, VA). Images were then montaged and edited using Adobe Photoshop. Genitalia were extracted, manually cleaned with minuten pins and $10 \% \mathrm{KOH}$ solution, and placed on glycerin slide mounts for observation and imaging. Scale bars were calibrated with an ocular micrometer using SPOT Advanced software on the images of the genitalia, which were taken with a digital camera attached to a Nikon SMZ1500 dissecting microscope. The final digital images were processed using Adobe Photoshop CS6. The distribution map was created with Quantum GIS Version 1.4.0.

Body measurements are defined as in Duran and Moravek (2013) and are as follows. The total body length excludes the labrum and is measured as the distance from the anterior margin of the clypeus to the elytral apex, including the sutural spine. The width of the pronotum is measured to include the lateral margins of the proepisterna. The width of the head is measured as the distance between the outer margins of the eyes. 


\section{Systematics}

Cicindelidia melissa Duran \& Roman, sp. n.

http://zoobank.org/E474385B-6B10-474A-A705-1F340C0B8FD5

Figs $2-10$

Type material. HOLOTYPE: đ̂̃, "USA, Arizona / Cochise Co / Barfoot Park (31.910, -109.273) D. Brzoska Aug 4, 2012" (USNM). ALLOTYPE: + , "USA, Arizona / Cochise Co / Barfoot Park (31.910, -109.273) D. Brzoska, Aug 4, 2012”(USNM).

PARATYPES: 1 ô, USA, Portal Ariz / Barfoot Park / 08-VIII-1957 8000ft. / leg

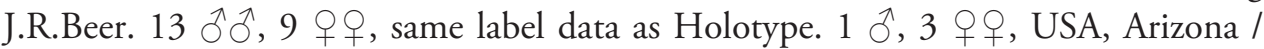
Cochise Co / Barfoot Park (31.910, -109.273) E. Sangregorio, Aug 4, 2009. 1 đ, 1 O, MEXICO, Chihuahua /Hwy.25 km157, .5 . S. Cusarare (27.332, -107.005) D. Brzoska, July 29, 2005. 1 ก, 1 \&, MEXICO, Chihuahua / Road to Z.A. Conjunio Anasezi / 1.6mi. S., .09mi. W-Madera (29.172, -108.173) D. Brzoska, July 11,1997. 1 ô, 1 q, MEXICO, Chihuahua / Creel, Divisidero Rd, 0.5m S Divisidero (29.528, -107.830) D. Brzoska, July 21, 2005. 1 ô, 1 q, MEXICO, Chihuahua / Hwy. 26, (Road to Topia), km 38 (25.063, -105.655) D. Brzoska, July 24, 1997. 2 đ소, 2 우우, MEXICO, Chihuahua / Chi Hwy. 25, E. of/ Guachochi-km104 / 26-VII-2005 R.L. Huber. 1 O , MEXICO; Chihuahua / Chi Hy 25 KM 157/ 20-VII-2005 R.L. Huber. 2 ふึં, MEXICO, Chihuahua / KM 25 Road to Batopilas / Quirare Village / 26-VII-

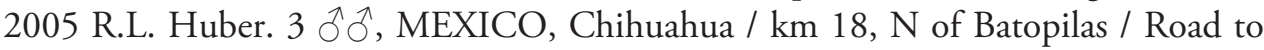
Creel / 21-VII-2005 R.L. Huber. 4 ô ${ }^{\lambda}, 9$ 우, MEXICO, Chihuahua / Chi Hwy 25

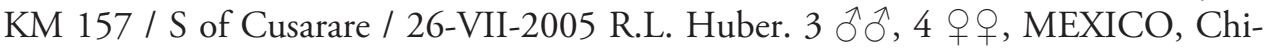
huahua / Ej.Guadalupe Victoria / 9.8mi W. San Jose Babicora / on Hwy 180, near km 14 /10-VII-1992 R.L. Huber. 1 + , MEXICO, Chihuahua / Hwy 1809.1 mi W / San Jose Bibicora / 13-VIII-1989 R.L. Huber. 1 + , MX / Chihuahua; Madera / June 1966 leg B. Rotger. 1 ô, MX Chihuahua / 20mi S la Junta / 29-Vi-1989 D.B. Thomas and J.C. Burne.

$5 \overbrace{}^{\Uparrow}, 2$ 우, MEX, Chihuahua /Road to Divisadero / (27'38.72N, 107'46.27W) / July 2, 1997 R.L. Huber. 5 §ึ, 6 우, MEX, Chihuahua / .5mi S Divisadero / (27'31.69N, 107'49.80W) / July12.1997, R.L. Huber. 2 Ђึ, 2 우, MEX, Chihuahua / S. of Creel / (27'41.64N, 107'35.14W) / July 12, 1997 R.L. Huber. 1 ô, 2 우, MEX, Chihuahua / Ejido Guadalupe / (29'12.86N, 107'52.81W) / July 11, 1997 R.L. Huber. 1 Oै, 2 우, MEX, Chihuahua / 2mi SW Madera / Rd to Sirupa /

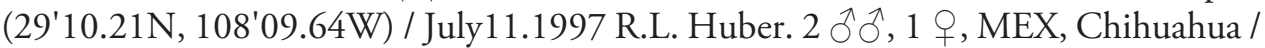
2.5mi W Madera / Rd to Huapaca Archaeo site / (29'10.29N, 108'10.40W) / July 11, 1997, R.L. Huber. 1 đ, 1 + MEX, Chihuahua / N of Madera / HWY 11, KM13.5 / (29'18.8N, 108'08.4W) / July 25,2008 R.L. Huber.

1 क, MEX, Chihuahua / Ejido Guadalupe Victoria / HWY 10, km 13.5 / (29'12.9N, 107'52.3W), 2300m / Aug 06, 2008 R.L. Huber. 1 ô, MEX, Chihuahua / Creel N. HWY 25 KM72 / (27'51.7N, 107'34.7W), 2362m / Aug 05, 2008 R.L. Huber. 1 o, MEX, Chihuahua / San Juanito, NNW / on Chi HWY110 KM5.5 / 


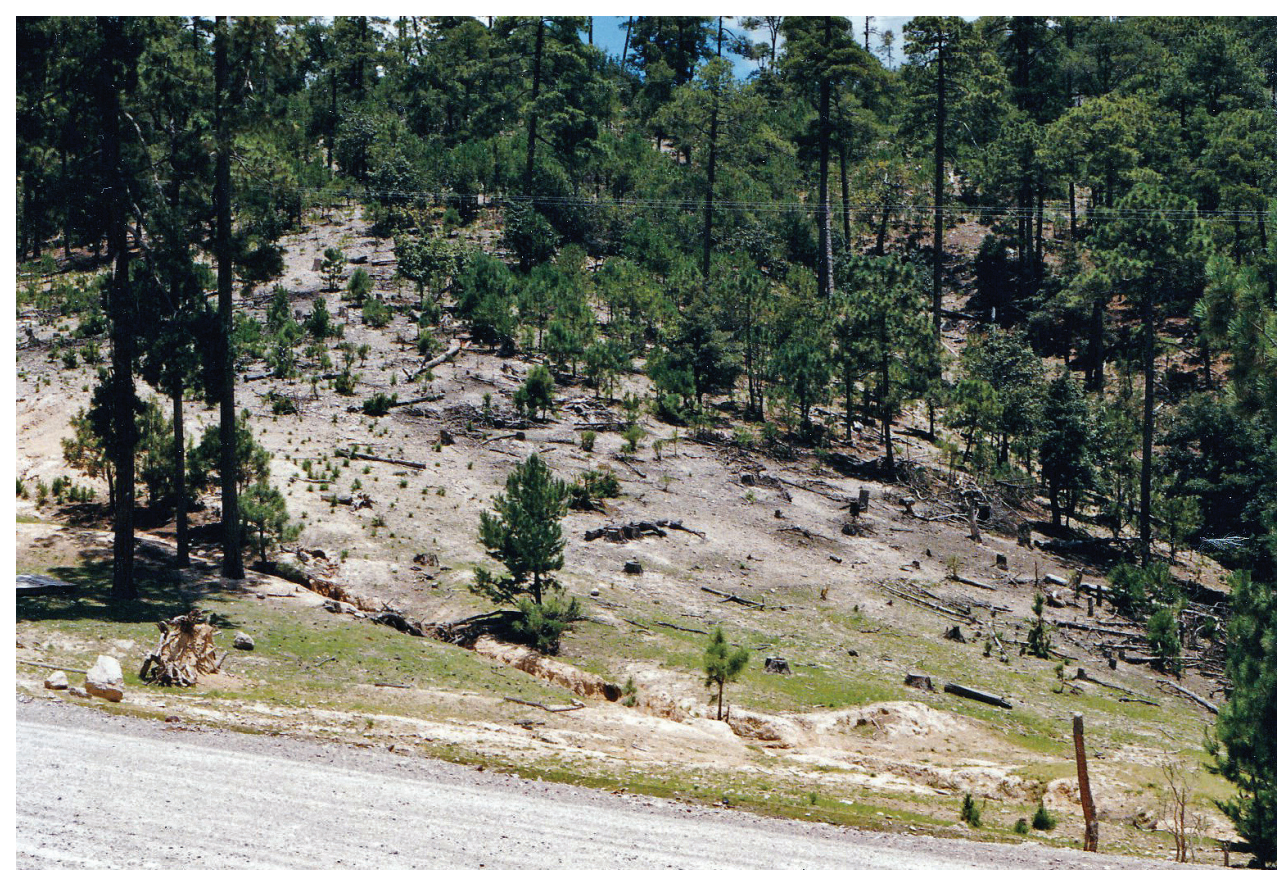

Figure I. Habitat of Cicindelidia melissa, Durango, Mexico. Photo by Walter Johnson.

(27'58.9N, 107'31.9W), 2440m / Aug 05.2008 R.L. Huber. 1 q, MEX, Chihuahua / 5KM S Madera, Rd to Sirupa / (29'09.0N, 108'10.6W), 2230m / July 25, 2008 R L Huber. 1 ơ, MX Chihuahua / Hwy 1809.1 mi W / San Jose Bibicora / 13-VIII -1989 R.L. Huber. 2 ふึَ, 3 q $q$, Durango Mexico / Lagoya de Golondrines / July 23, 1997 / Walter N Johnson. $2 \hat{\jmath} \hat{\sigma}, 1$ q, Durango Mexico / Rancho Chapultepec / July 23, 1997 / Walter N Johnson. 3 ふึَ, 1 D Durango Mexico / Los Altares, HWY 26 / July 24, 1997 / Walter N Johnson. 3 ふึ̄̃, 1 ㅇ, Durango Mexico / Los Ranes / July 23, 1997 / Walter N Johnson. 1 ㅇ, Durango Mexico / Los Ranes / July 24, 1997 / Walter N Johnson. 2 ठึ่, Durango Mexico / 2.5mi E. Los Ranes / July 23, 1997 / Walter N Johnson. 9 ふึग̃, 5 우, MEXICO Chihuahua / Ejodo Guadalupe Victoria / 9.8 mi W S.J. Bibicora / 10-VII-1992 J.Stamatov. 4 đ̃̂, 6 q $q$, MEXICO Chihuahua / Hy 25, km157.5 2172m / S of Cusarare (27º19.9 107³0.3) / July-26-2005 Coll: J. Stamatov. 1 ㄱ, 3 우, MEXICO Durango / 13.5 mi E of Canelas / 15-VII-1997 / Coll: J. Stamatov.

All type specimens labelled: HOLOTYPE, ALLOTYPE or PARATYPE, respectively.

Diagnosis. This species can be distinguished from all other similar Cicindelidia by its dark green-violet abdominal venter with the two apical segments dull orange or orange-brown, a brassy-cupreous head and pronotum with metallic blue reflections in sulci, small shallow subsutural foveae present in most individuals, and microserrate elytral apices. It inhabits rocky upland soils in ponderosa pine forests above $2000 \mathrm{~m}$ (Fig. 1). C. sedecimpunctata (Klug, 1834) has an entirely orange-red to orange-brown 


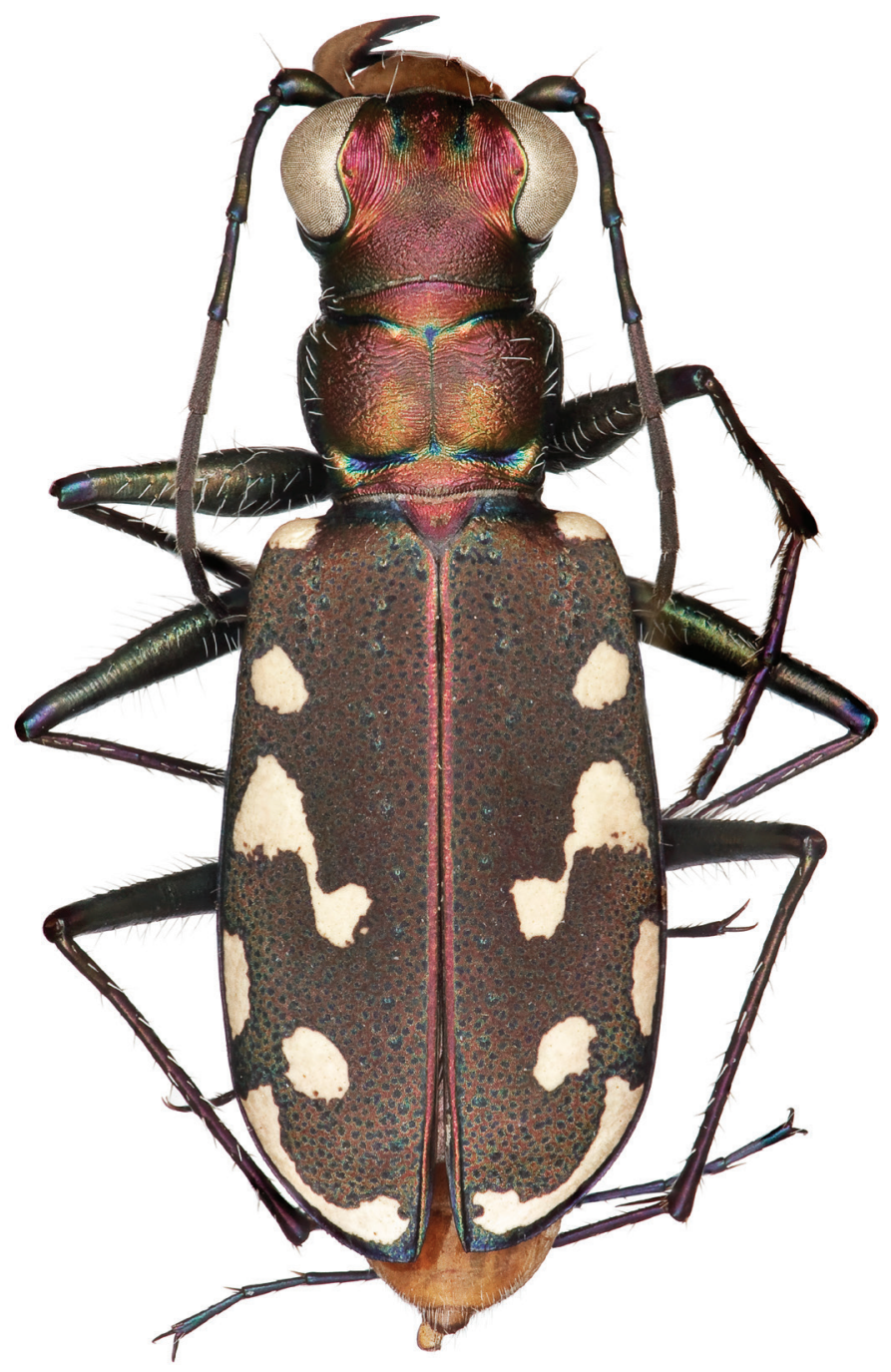

Figure 2. Dorsal habitus of male (holotype).

abdominal venter, a more uniform dull brown dorsal coloration, and lacks apparent subsutural foveae. It also differs from the new species by inhabiting muddy ground at nearly any elevation. C. nebuligera (Bates, 1890) has dark elytral infuscations that surround the middle band, and lacks elytral apical microserrations. It may be found in similar habitats, but is apparently allopatric with the new species and does not appear to be restricted to elevations above $2000 \mathrm{~m}$.

Description. Small to medium sized Cicindelidia. Body (Figs 2-5) length 7.90$10.50 \mathrm{~mm}$, mean $99.7 \mathrm{~mm}$, mean $09.0 \mathrm{~mm}$. Head (Figs 6-7) slightly wider than pronotum, width $2.3-2.7 \mathrm{~mm}$, brassy-cupreous red with metallic blue and cupreous reflections present in sulci, all head portions glabrous except for 2 supraorbital setae 


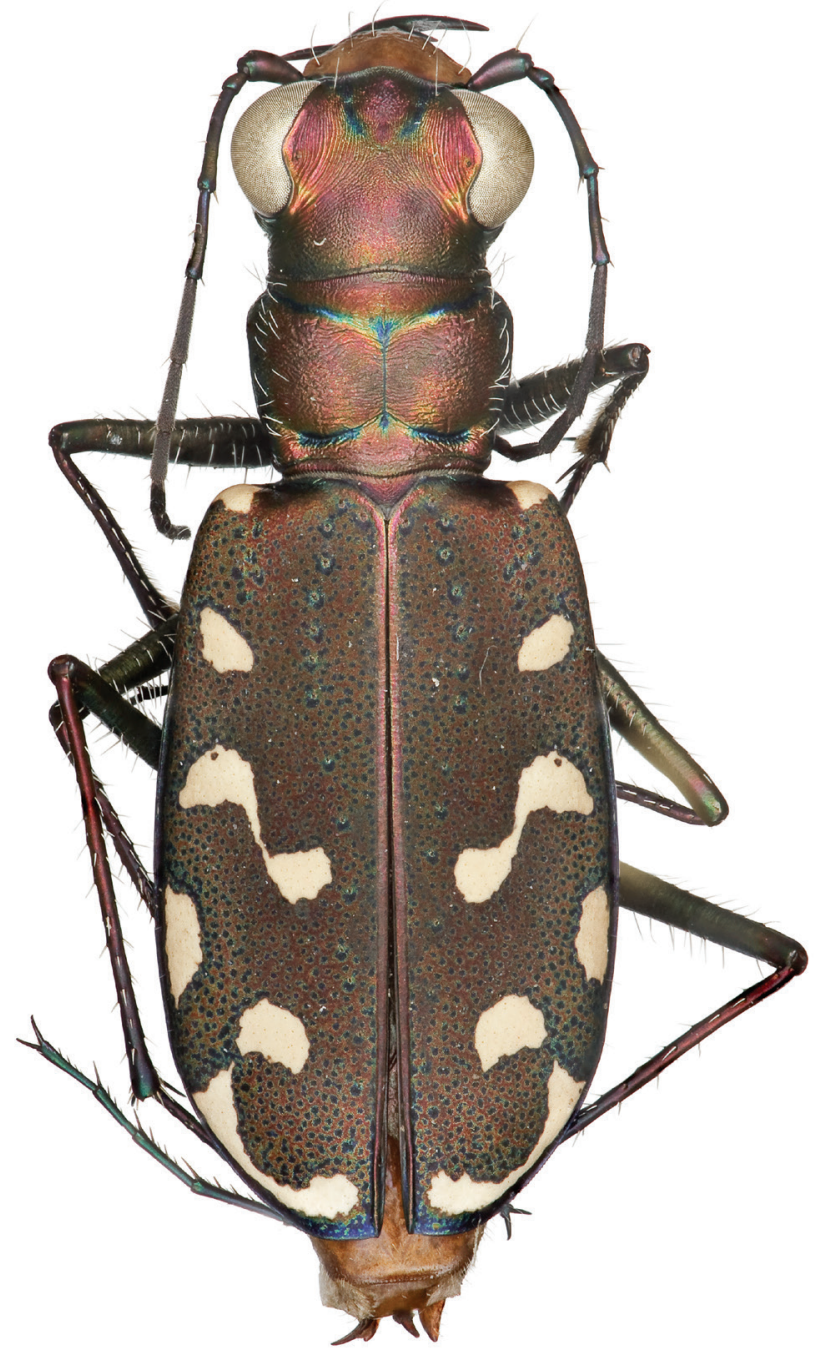

Figure 3. Dorsal habitus of female (allotype).

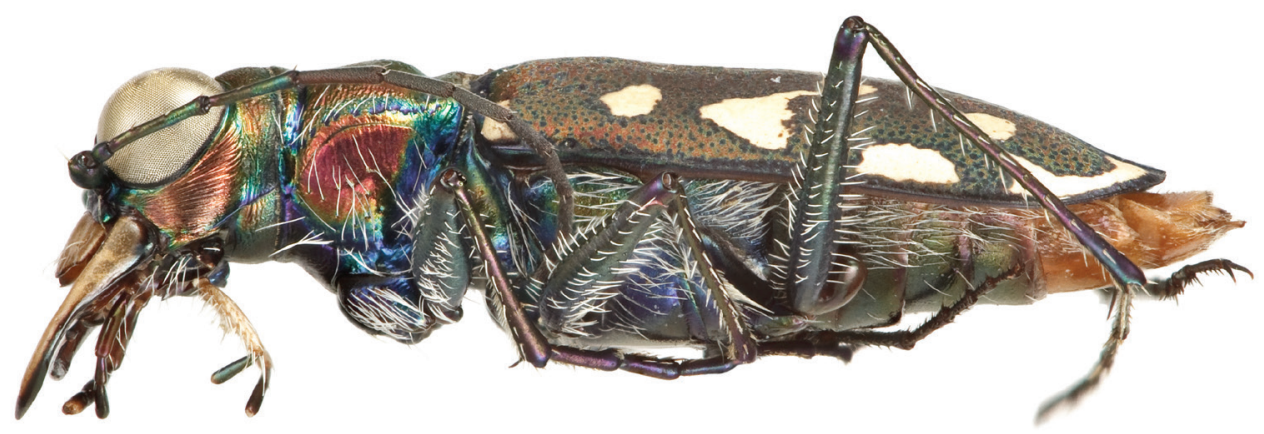

Figure 4. Lateral habitus of male (holotype). 


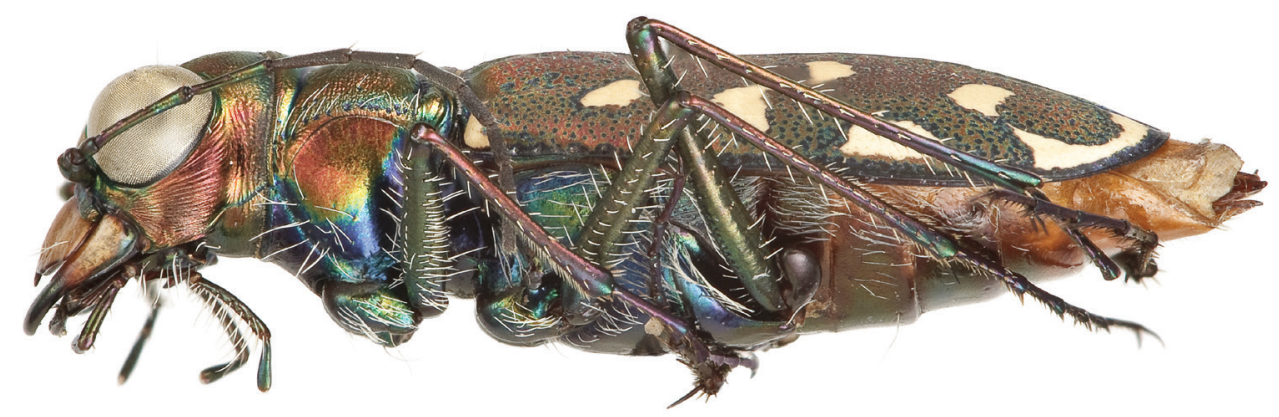

Figure 5. Lateral habitus of female (allotype).

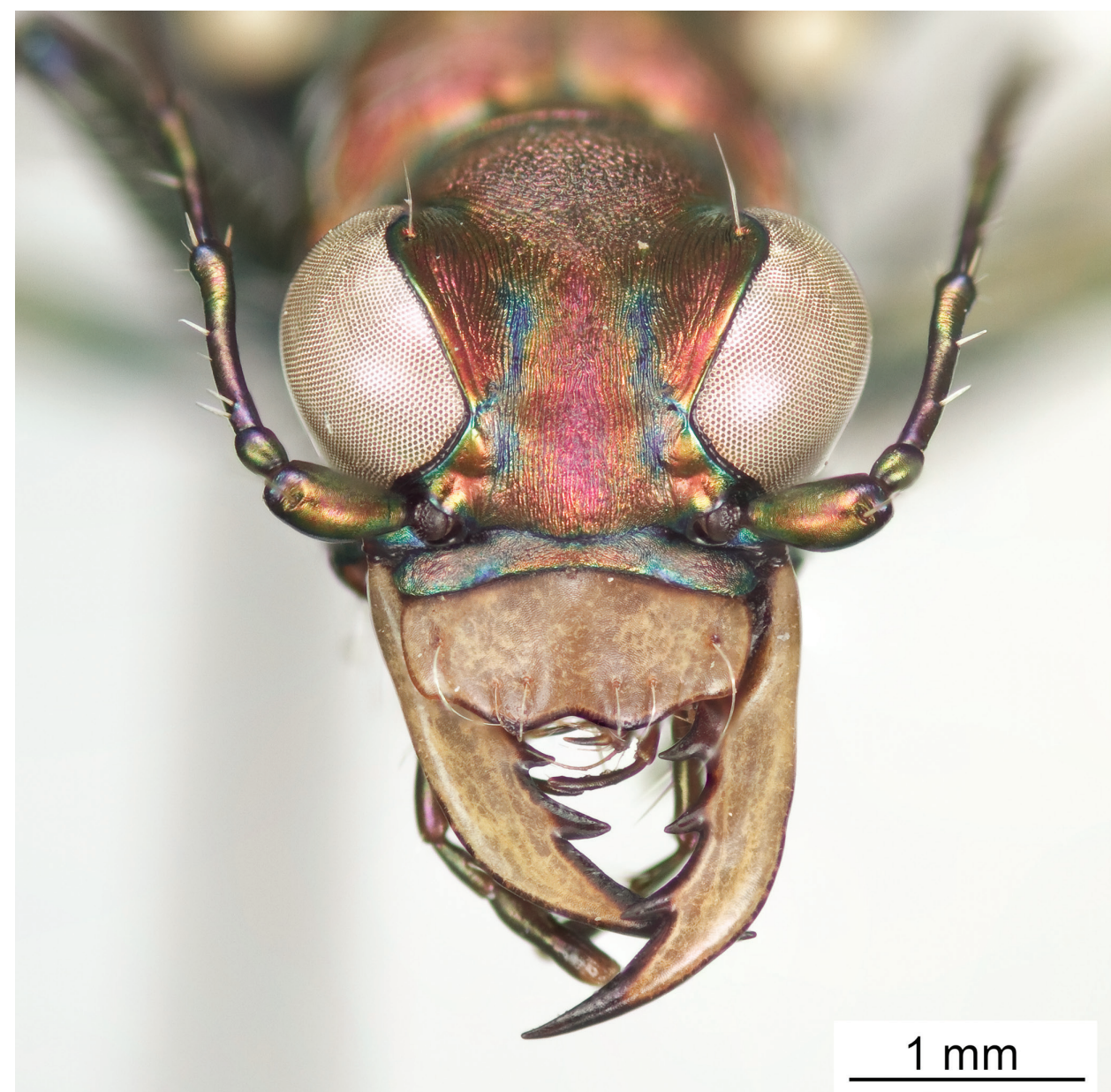

Figure 6. Frontal habitus of male (holotype). 


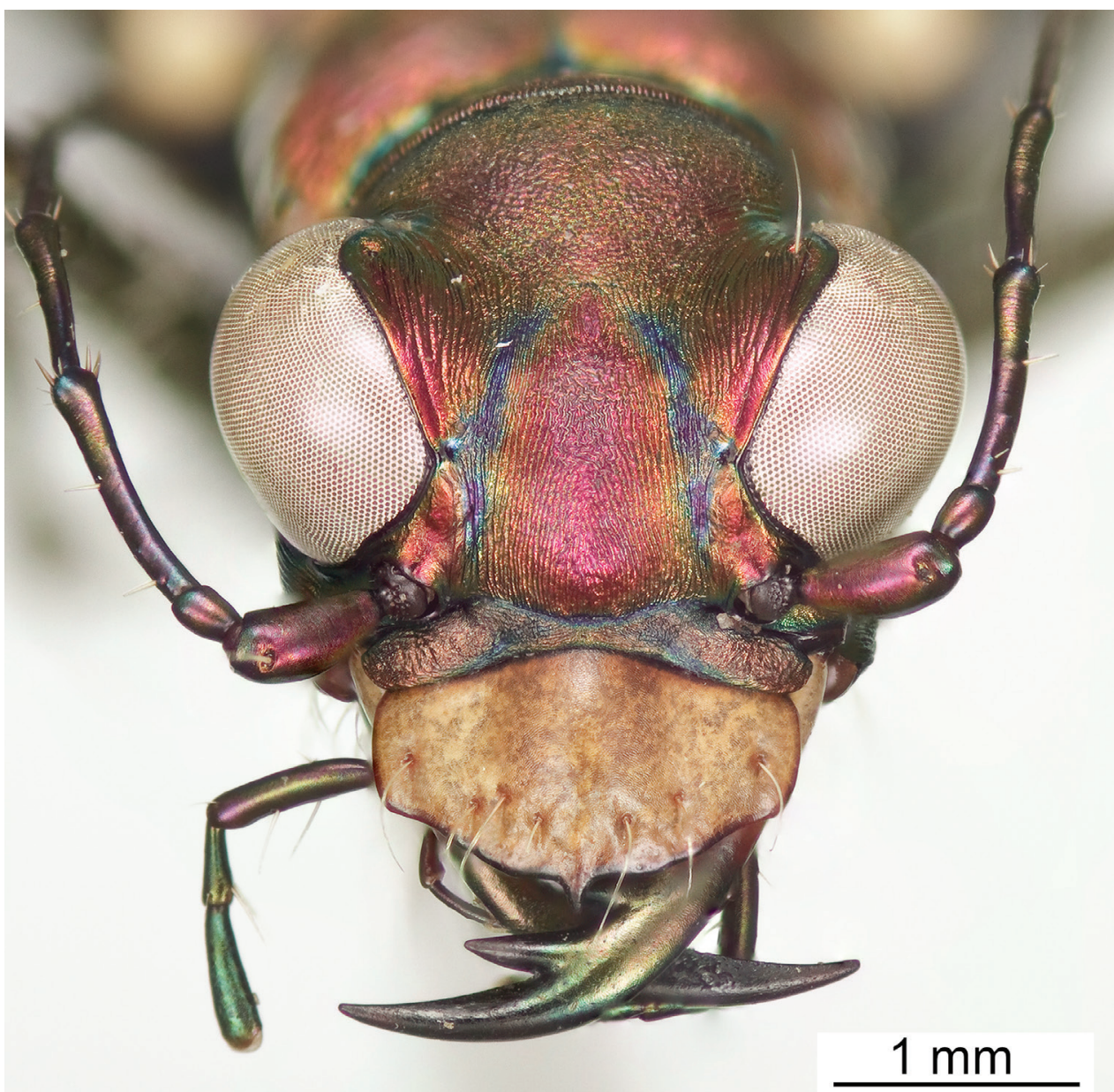

Figure 7. Frontal habitus of female (allotype).

next to each eye. Frons concave in median area especially in male, bulging towards slightly convex near anterior margin, clearly delimited from clypeus, gradually blending into vertex. Frons surface with distinct longitudinal striae especially in lateral areas bordering eyes, vermiculate-striate in median area. Vertex dark brassy colored, slightly convex, with surface indistinctly finely vermiculate, posterior areas with cupreous-olive lustre. Genae bright polished copper with deep longitudinal striae abruptly ending at border of vertex. Clypeus cupreous blending to blue along borders, irregularly wrinkled to finely vermiculate. Labrum with 6 setae, ochre-testaceous with a thin dark brown to black border; female labrum rather long, length $0.60-0.90 \mathrm{~mm}$, width $1.3-1.6 \mathrm{~mm}$, with single median tooth; male labrum short to medium, length $0.45-0.80 \mathrm{~mm}$, width $1.2-1.7 \mathrm{~mm}$, shape varies from nearly straight across anterior edge with only slightly protruding median tooth to an unusual slightly notched median edge (see holotype). 


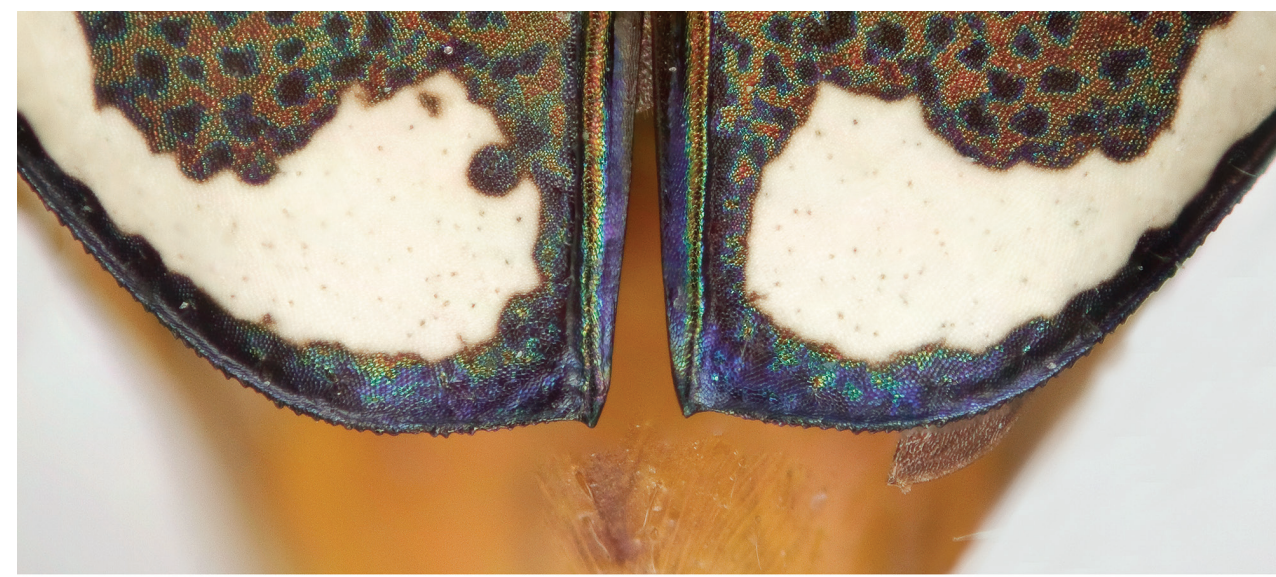

$1 \mathrm{~mm}$

Figure 8. Elytral apex, showing microserrations and apical spine.

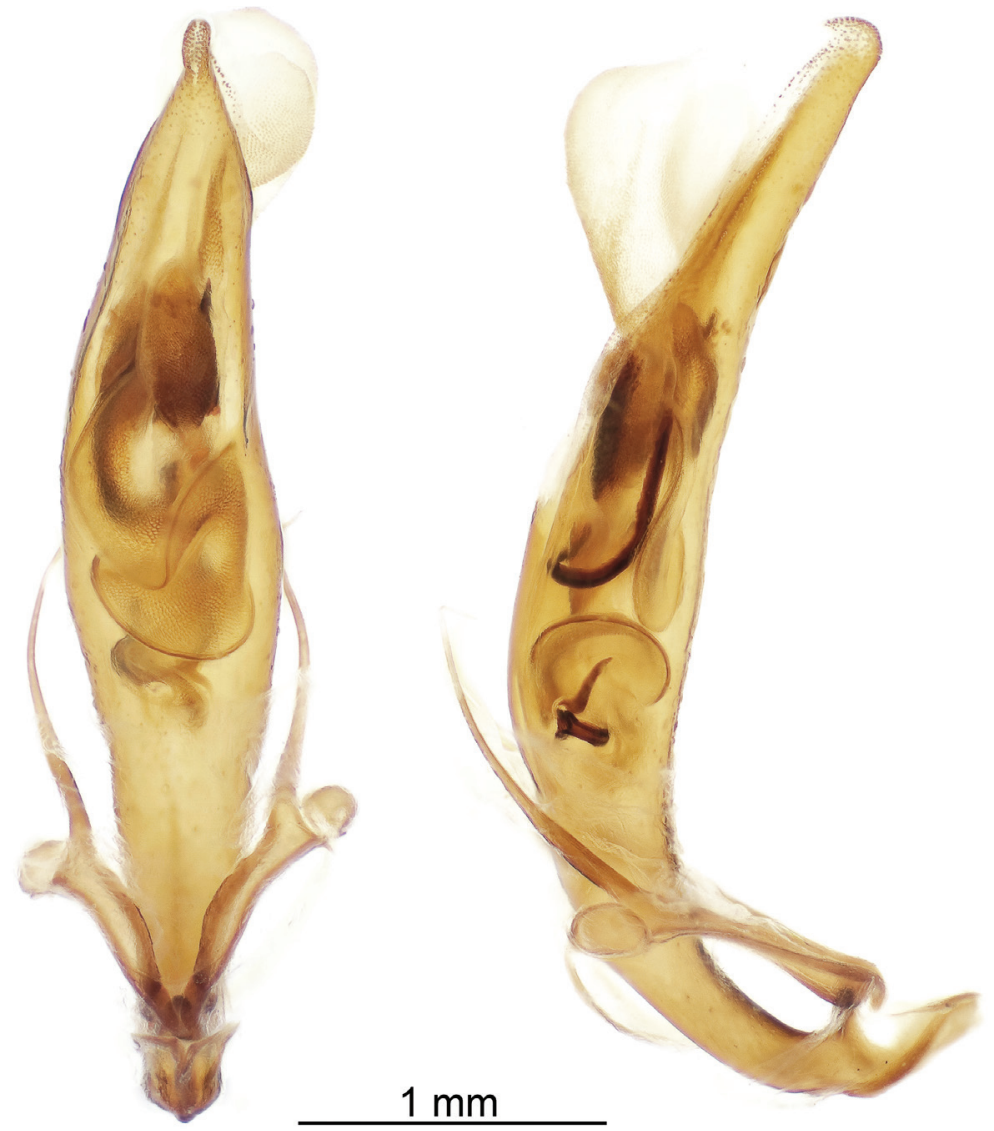

Figure 9. Cleared aedeagus in ventral and lateral (left side) views. 


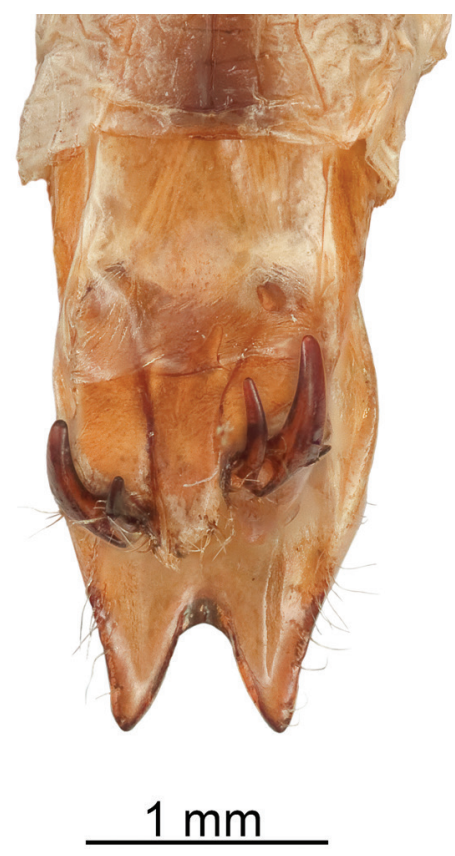

Figure 10. Ovipositor in ventral view.

Mandibles medium-sized, ochraceous in male, dark ochraceous with metallic gold, green and black reflections in female, teeth of both sexes dark testaceous along edges. Maxillary palpi dark testaceous with metallic reflections; apical segment usually darker than sub-apical segment. Labial palpi in male ivory to pale yellow-ochre in male with dark metallic green to violet apical segment, in female entirely dark testaceous with metallic reflections throughout. Antennae normal length, reaching humerus to basal third of elytron, slightly longer in male than female; scape dark testaceous to black with metallic reflections of cupreous, gold, and violet, with a single apical seta; pedicel dark testaceous with metallic reflections of cupreous, gold, and violet, lacking any setae; flagellum dark testaceous, antennomeres 3-4 with metallic cupreous and violet reflections, with ring of apical setae and additional sparse setae throughout, antennomeres 5-11 dull textured without metallic reflections and possessing erect setae in apical rings only, covered with fine pubescence throughout.

Thorax. Pronotum $1.70-2.50 \mathrm{~mm}$ in width, slightly polished with metallic finish, brassy-cupreous with metallic blue or blue-green sulci, slightly wider than long, nearly trapezoidal in shape and widest near anterior margin, width to length ratio 1.2 to 1.3 , setae sparse and present along lateral third of dorsal surface; disc finely rugose to vermiculate with thin but distinct median line and deeply impressed sulci; notopleural sutures clearly defined, not visible from dorsal view; proepisternum bright polished copper with gold and green reflections more ventrally, abruptly transitioning to blueviolet on ventral third and posterior third, in male setae present throughout surface of 


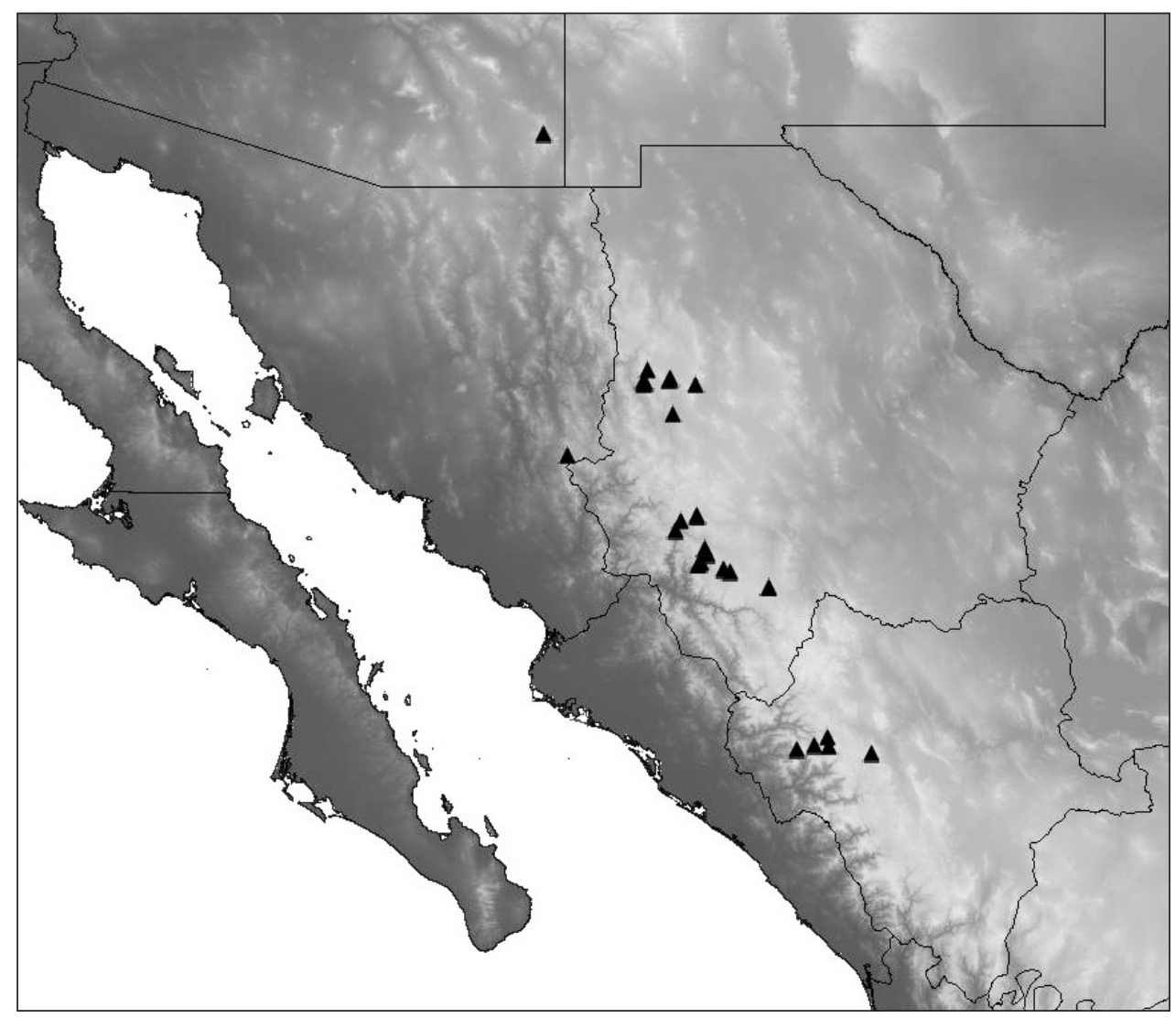

Figure I I. Distribution map of the known localities for Cicindelidia melissa. Lines indicate political boundaries of states in Mexico and the United States. Shading indicates topographical relief.

proepisternum, but in female setae are typically sparsely present only along ventral third and along anterior margin; all other ventral segments of thorax are glabrous, dark blueviolet to black with greenish reflections. Elytra elongate, 5.1-6.7 $\mathrm{mm}$ length, shape similar in both sexes, but slightly wider in female, especially toward apical third; sutural spine small to nearly absent, fine microserrations present on elytral apices (Fig. 8), extremely fine to nearly indistinct in some individuals; elytral dorsal surface relatively flat, not markedly convex, texture dull throughout with slight metallic sheen near pronotal base in a some individuals, elytral coloration mostly a dull cupreous brown color, under magnification this color is comprised of the pointillistic mixing of mostly cupreous ground color with many small patches of dark blue-violet bordered in green; subsutural foveae are present, but nearly indistinct in a small percentage of individuals; elytral maculations white, and consist of a small humeral and posthumeral spot, a moderately short middle band which does not touch the margin and with "knee" and "foot" regions connected with a thin but complete line, an isolated marginal spot between the middle 
band and apical lunule, and an apical lunule comprised of a subapical spot that is broken from the thin apical line; epipleura dark blue-violet to black.

Legs. Procoxae and mesocoxae dark metallic green to black, covered in dense setae; metacoxae dark metallic green to blue-violet to black, with a single apical setae present; trochanters glabrous, dark green to violet-black; femora dark metallic green with blue-violet reflections near the insertion of the tibia, femoral surface with rows of erect white setae dorsally and ventrally; tibiae violet to dark cupreous with dark green reflections near the apices, clothed with white setae that are sparser and shorter than those of the femora; tarsi violet with blue reflections dorsally, first three dilated protarsomeres in male with dense greyish-white setal pad.

Abdomen. Ventrites $1-4$ dark violet with strong metallic greenish reflections throughout most surfaces, dark orange to testaceous coloration along lateral edges in some individuals, setae present mostly along lateral third of each ventrite; ventrites 5-6 orange to dark orange-testaceous throughout, setae present along lateral margins, but often abraded.

Reproductive structures. Aedeagus (Fig. 9) elongate, widest in middle, length $3.40-3.60 \mathrm{~mm}$, width $0.65-0.75 \mathrm{~mm}$, slightly arcuate in ventral view, apical portion produced into a narrow tip with a slight hooklike projection; internal sac and sclerites prominent in cleared aedeagus and visible both ventrally and laterally. Ovipositor (Fig. 10) deeply notched and possessing two heavily sclerotized bifurcated hooks ventrally, setae present especially along lateral margins and near base of hooks.

Etymology. This new Cicindelidia is named after the first author's wife, Melissa, for her constant support, love, and friendship.

Distribution and habitat. C. melissa is currently known from northwestern Durango, western Chihuahua, eastern Sonora, and southeastern Arizona. All known occurrences are from forested hillsides and trails above $2000 \mathrm{~m}$. Typical habitats contain rocky substrates derived from limestone and/or rhyolite, with forest cover generally dominated by Ponderosa pine. This species is mostly active following monsoon rains, but frequents upland areas and is not closely associated with muddy or riparian microhabitats.

\section{Discussion}

Given the superficial similarity to C. sedecimpunctata in dorsal habitus, C. melissa may have been overlooked and assumed to be a form of that widely distributed species. However, despite the general resemblance, multiple diagnostic morphological characters exist, as discussed above. Previous authors acknowledged that additional cryptic species may be present in the C. sedecimpunctatalrufiventris group (Cazier 1954, Murray 1980), but the taxonomy of the group has not been revisited since. The relatively small number of available specimens of $C$. melissa in museums is likely due to its occurrence in less-accessible geographic areas and in a habitat that is less visited by most tiger beetle collectors.

It is interesting to note that the ecological differences between $C$. melissa and C. sedecimpunctata are stark, and habitat alone separates the two species in almost all cases. Tiger beetle taxonomy has relied nearly exclusively on fixed morphological characters to date, yet we believe that this present example underscores the importance of habitat 
and ecological factors that may not be apparent when comparing dead specimens of tiger beetles. Given the ecological and morphological similarities and apparently allopatric ranges, we propose that $C$. melissa and $C$. nebuligera are most closely related. Increasingly, higher-level and species-level phylogenies are based on molecular data, in part or entirely, and recent authors have examined relationships of Nearctic tiger beetles (Vogler et al 2005), although Mexican species were not as well represented. The authors of this description are conducting a thorough revision of Cicindelidia using a combination of molecular, morphological, and ecological characters, and this species description is the first of a series of papers on the group.

\section{Acknowledgements}

The authors thank David W. Brzoska, Ronald L. Huber, John Stamatov, and Eric Sangregorio for providing specimens for this study. We also thank Walter Johnson for providing specimens and for the habitat photograph used in Figure 1. The first author thanks Floyd Shockley (Smithsonian Institution) for his help with preparation of the aedeagus and for comments on the manuscript. We also thank Karie Darrow (Smithsonian Institution) for taking the images for Figures 2-10. Finally, we thank two anonymous reviewers for providing comments on the manuscript.

\section{References}

Bates HW (1890) Additions to the Cicindelidae fauna of Mexico, with remarks on some of the previously-recorded species. The Transactions of the Entomological Society of London for the year 1890: 493-510.

Cazier MA (1954) A review of the Mexican tiger beetles of the genus Cicindela (Coleoptera, Cicindelidae). Bulletin of the American Museum of Natural History 103: 227-310.

Duran DP, Moravek J (2013) A new species of the genus Pentacomia from Panama (Coleoptera: Cicindelidae). Acta Entomologica Musei Nationalis Pragae 53(1): 49-57.

Klug JCF (1834) Uebersicht der Cicindeletae der sammlung des Berliner Museum. Jahrbücher der Insectenkunde, mit besonderer Rücksicht auf die Sammlung im Konigl. Museum zu Berlin, 1, 296 pp.

Murray RR (1980) Systematics of Cicindela rufiventris Dejean, Cicindela sedecimpunctata Klug, and Cicindela flohri Bates (Coleoptera: Cicindelidae). PhD dissertation, Texas A\&M University, $301 \mathrm{pp}$.

Rivalier E (1954) Démembrement du genre Cicindela Linné. II. Faune américaine. Revue Française d'Entomologie 21(4): 249-268.

Vogler AP, Cardoso A, Barraclough TG (2005) Exploring Rate Variation Among and Within Sites in a Densely Sampled Tree: Species Level Phylogenetics of North American Tiger Beetles (Genus Cicindela). Systematic Biology 54(1): 4-20. doi: 10.1080/10635150590906028

Wiesner J (1992) Verzeichis der Sandlaufkäfer der Welt. Verlag, Erna Bauer, Keltern-Weiler, Germany, 366 pp. 